\title{
Surto concentrado de \\ choque tóxico estreptocócico
}

\section{Concentrated outbreak of streptococcal toxic shock}

Bernardino Geraldo Alves Souto ${ }^{1}$, Marcelo Rigueti ${ }^{2}$, Alessandra Cristina Guedes Pellini ${ }^{3}$, Gisele Dias de Freitas Lima², Maria Emília Braite de Oliveira²

'Departamento de Medicina da UFSCar - São Carlos (SP), Brasil.

2Programa de Treinamento em Epidemiologia Aplicada aos Serviços do Sistema Único de Saúde do Estado de São Paulo (SUS) - São Carlos (SP), Brasil.

${ }^{3}$ Centro de Informações Estratégicas de Vigilância em Saúde; Centro de Vigilância Epidemiológica Prof. Alexandre Vranjac; Coordenadoria de Controle de Doenças da Secretaria de

Estado da Saúde de São Paulo - São Carlos (SP), Brasil.

DOI: http://dx.doi.org/10.7322/abcshs.v38i2.14

\section{RESUMO}

Introdução: Síndrome do Choque Tóxico (SCT) é um processo autoinflamatório imunomediado, pouco frequente, mas clinicamente muito grave. Instala-se abruptamente e, comumente, leva a pessoa à morte em poucas horas. Um dos seus determinantes é a infecção por Streptococcus pyogenes. Não há relatos de epidemias desse agravo, mas surtos eventuais acontecem e estão aumentando de frequência. Este artigo relata uma experiência relacionada a um surto de SCT estreptocócico, vivenciada pelo Serviço Municipal de Vigilância Epidemiológica de São Carlos, SP, juntamente com o Centro de Vigilância Epidemiológica do Estado de São Paulo. Relato de caso: Diante da morte de duas pessoas residentes no mesmo domicílio, ocorridas no mesmo dia em condições inusitadas e idênticas, estratégias epidemiológicas descritivas permitiram a aplicação imediata de medidas de controle e assistência. Dez dias depois houve a confirmação de que se tratava de SCT estreptocócico. Agravos emergentes e reemergentes têm exigido dos Serviços de Vigilância em Saúde um estado de alerta e agilidade no trato com problemas inusitados e agudos. A ferramenta disponível mais eficiente é, ainda, a epidemiologia descritiva, devido ao seu potencial para identificar os meios de controle de agravos antes mesmo do respectivo diagnóstico. Conclusão: Surto de SCT estreptocócico é um problema reemergente, vêm aumentando de frequência, ocorre abruptamente e apresenta elevada letalidade. É necessário, pois, especial atenção dos Serviços de Vigilância em Saúde a essa possibilidade diante da circulação de infecções por Staphylococcus ou Streptococcus ou quando ocorrerem óbitos concentrados a partir de eventos de rápida evolução clínica em pessoas previamente sadias.

Palavras-chave: choque séptico; vigilância epidemiológica; epidemiologia descritiva; Streptococcus pyogenes; doenças transmissíveis emergentes; surtos de doenças.

\begin{abstract}
Introduction: Toxic Shock Syndrome (TSS) is a self-inflammatory immune-mediated, infrequent, but, clinically very serious process. It is established abruptly and, commonly, progresses to death in a few hours. One of its triggers is infection by Streptococcus pyogenes. There are no reports of severe epidemics, but outbreaks occur and are increasing in frequency. This paper reports an experience related to an outbreak of streptococcal TSS, experienced by the Municipal Epidemiological Surveillance Service of São Carlos, SP, together with the Centre of Epidemiological Surveillance of State of Sao Paulo, Brazil. Case report: Facing the death of two persons residing in the same household, which occurred on the same day in unusual and identical conditions, descriptive epidemiological strategies allowed the immediate implementation of control measures and assistance. Ten days later there was confirmation that it was streptococcal TSS. Emerging and reemerging diseases has required of the services of health surveillance alertness and agility in dealing with unusual and acute problems. The most efficient tool available is, still, the descriptive epidemiology due to its potential to identify the means of control of aggravations even before their diagnosis. Conclusion: Outbreaks of streptococcal TSS is a reemerging problem that is increasing frequency, occur abruptly and have high lethality. It is necessary, therefore, special attention of the Health Surveillance Services in face of the possibility of circulation of infections by Staphylococcus or Streptococcus, or when deaths occur from events of rapid clinic progression in previously healthy people.
\end{abstract}

Keywords: shock, septic; epidemiological surveillance; epidemiology, descriptive; Streptococcus pyogenes; communicable diseases, emerging; disease outbreaks. 


\section{INTRODUÇÃO}

A Síndrome do Choque Tóxico (SCT) é um processo autoinflamatório induzido por mediadores imunológicos em resposta a algumas infecções, especialmente as causadas por Staphylococcus aureus ou Streptococcus pyogenes. Caracteriza-se por grave disfunção multiorgânica mediada por evento tóxico-inflamatório, curso clínico rápido e progressivo, irreversível em até $70 \%$ das pessoas que o manifestam ${ }^{1-4}$.

A invasão do organismo por uma das bactérias citadas pode ocorrer por diversas vias, mas tem sido mais frequentemente descrita a partir de lesões cutâneas ${ }^{3,4}$.

O Streptococcus pyogenes é um coco Gram positivo, também conhecido como Estreptococo beta-hemolítico do grupo A de Lancefield. Pode ser encontrado em vias aéreas superiores ou na pele de pessoas assintomáticas, causar infecções de baixa gravidade como faringite ou impetigo, e determinar quadros invasivos graves, a exemplo da fasciite necrotizante, pneumonia, empiema, meningite, artrite e osteomielite, entre outros ${ }^{1,3,4}$.

A resposta imunoinflamatória induzida por esse patógeno ou suas exotoxinas pode, em alguns casos, produzir lesões ou disfunções orgânicas no corpo da pessoa infectada. É possível que essas alterações se manifestem na vigência da infeccção aguda, ou tardiamente, depois que a doença aguda já tenha sido resolvida. No primeiro caso, podem surgir quadros benignos como exantemas e artrites reativas ou complicações letais, incluindo a SCT. Já no segundo, podem surgir cardiopatias estruturais com comprometimento valvar, alterações articulares (febre reumática) ou comprometimento renal (glomerulonefrite difusa aguda) ${ }^{1-5}$.

Em países desenvolvidos, a incidência de infecções invasivas por Streptococcus pyogenes varia de 0,3 a 4,8 casos por 100.000 habitantes, com letalidade que pode chegar a $53,8 \%$ - um dos determinantes da letalidade é a SCT ${ }^{6}$.

A esse respeito, o Working Group on Severe Streptococcal Infections do Centers for Disease Control and Prevention (CDC) de Atlanta, EUA, define como critério para um caso confirmado de SCT estreptocócico o isolamento de Streptococcus pyogenes em um sítio normalmente estéril do organismo de uma pessoa com síndrome de choque de início súbito e rapidamente progressivo ${ }^{7}$.

A patogenia da SCT estreptocócico ainda não é completamente conhecida, mas acredita-se que, a depender da interação entre a bactéria e o organismo infectado, exotoxinas pirogênicas do $S$. pyogenes, também relacionadas ao exantema da escarlatina, possam atuar como superantígenos indutores da proliferação e da ativação de linfócitos $\mathrm{T}$ e macrófagos, resultando em desregulação imunológica autoinflamatória derivada da produção excessiva de citocinas. Essa desregulação, por sua vez, pode induzir a uma falência circulatória periférica capaz de determinar disfunção multiorgânica e morte ${ }^{1-6}$.

Do ponto de vista epidemiológico, embora a transmissão secundária não seja frequentemente descrita entre contatos ou comunicantes intradomiciliares, admite-se que fatores ambientais, como a aglomeração de pessoas em espaços com ventilação reduzida, favoreçam a transmissão do Streptococcus pyogenes e, consequentemente, a possibilidade de surtos concentrados de $\mathrm{SCT}^{4,8}$.

Assim, tais surtos têm sido descritos em comunidades, lares ou hospitais, mas agregados intradomiciliares com evolução letal não são comuns. Do mesmo modo, não há relatos de epidemias de SCT estreptocócico ${ }^{3,4,8,9}$

A seguir é apresentada uma reflexão crítica sobre uma experiência com a investigação epidemiológica de um surto intradomiciliar de SCT estreptocócico que culminou na morte de dois irmãos dentro da mesma residência em menos de 24 horas.

O objetivo é alertar gestores e profissionais da assistência e da vigilância à saúde para a importância clínica e epidemiológica de surtos de choque tóxico estreptocócico como agravo emergente, além de evidenciar o processo da citada investigação.

\section{RELATO DE CASO}

Em 8 de setembro de 2011 (Semana Epidemiológica 32), a Divisão de Vigilância Epidemiológica da cidade de São Carlos (SP) foi informada de que dois irmãos adultos jovens, previamente sadios e de bom nível socioeconômico, residentes no mesmo domicílio, morreram no mesmo dia devido a uma falência multiorgânica de surgimento abrupto e evolução clínica rápida e refratária às medidas terapêuticas convencionais. Os sintomas que possivelmente os conduziram à morte tiveram início uma semana antes dos óbitos e eram muito semelhantes nos dois casos. Imediatamente foi constituído um comitê especial para a respectiva investigação epidemiológica, o qual recebeu apoio direto, em campo, da equipe do Programa de Epidemiologia Aplicada aos Serviços do Sistema Único de Saúde de São Paulo (EPISUS-SP) do Centro de Vigilância Epidemiológica Prof. Alexandre Vranjac da Secretaria de Estado da Saúde de São Paulo, que atuou sob a supervisão da Central/Centro de Informações Estratégicas de Vigilância em Saúde (CIEVS), da Divisão de Doenças Respiratórias e da Direção do mesmo órgão.

Inicialmente, a investigação teve como objetivos bloquear o fator causador das mortes para impedir novas ocorrências e identificar, descrever e controlar o respectivo agravo. Para satisfazer o primeiro item, foi necessário determinar se a causa das mortes era uma doença transmissível ou não e, sendo transmissível, identificar o modo e a via de transmissão para que fosse possível o desencadeamento de ações de bloqueio. Para isso, foi aplicado um questionário semiestruturado aos familiares das pessoas que faleceram e aos comunicantes sintomáticos, bem como coletadas informações quanto ao exame clínico e laboratorial desses sujeitos em busca de uma etiologia específica.

Do ponto de vista epidemiológico estratégico, o primeiro objetivo precisava ser atingido dentro do prazo mais curto possível; ou seja, independente de se conhecer qual era o agravo, era necessário saber se o mesmo era transmissível e como evitar a sua transmissão, ou, caso não fosse transmissível, como era adquirido. A expectativa era de que, a partir deste esclarecimento, seria 
possível alcançar o controle epidemiológico na comunidade até que o problema fosse melhor conhecido.

Desse modo, a primeira medida do Comitê foi a realização de um inquérito epidemiológico a partir do primeiro caso letal, utilizando a estratégia da bola de neve para a captação de novos casos ou casos suspeitos, no sentido de verificar se eles tinham vínculo entre si ou com os casos que evoluíram para óbito.

A estratégia se caracteriza por um modelo de investigação em que uma pessoa investigada indica outra que tenha tido sinais ou sintomas semelhantes. Essa outra também é investigada e indica uma próxima e, assim, sucessivamente ${ }^{10}$.

Resultados iniciais da investigação corroboraram para a identificação de nove comunicantes ou contactantes do caso-índice (o primeiro que faleceu): um deles também morreu, três tiveram manifestações leves e autolimitadas, três não apresentaram nenhuma manifestação clínica e dois foram hospitalizados com sintomatologia moderada. Nenhum caso teve manifestação clínica ou laboratorial de evento hemorrágico.

Até esse momento, portanto, havia dez pessoas epidemiologicamente vinculadas ao agravo investigado: sete sintomáticas, das quais duas faleceram (letalidade de 28,6\% entre os sintomáticos); e três assintomáticas. A mortalidade específica, até então, atingia 0,89 por 100.000 habitantes.

Em relação aos indivíduos que faleceram por SCT, eram dois irmãos que moravam na mesma casa, um do sexo masculino, com 31 anos de idade (caso-índice), e outro do sexo feminino, com 39 anos. Ambos apresentaram febre, dor de garganta, mialgia, dispneia e exantema, e morreram em 8 de setembro de 2011, às 5 h e às $22 \mathrm{~h} 50$, respectivamente. O homem se encontrava no nono dia de início dos sintomas, e a mulher, no sétimo (Figura 1).

A análise dos dados do inquérito preliminar identificou vínculo epidemiológico entre os investigados que apontava para um eixo de transmissão interpessoal direta, dependente de contato íntimo ou prolongado, com elevada taxa de ataque intradomiciliar. O período de incubação estimado foi de cerca de uma semana, e complicações graves foram notadas ao final da primeira semana de início dos sintomas. A transmissibilidade também foi maior ao longo da primeira semana. As pessoas que tiveram manifestações moderadas ou sofreram complicações graves tinham entre 20 e 40 anos de idade, independente do sexo.

Do ponto de vista clínico, quem adoeceu teve início súbito e cursou, principalmente, com febre, mialgia, exantema, indisposição e dor de garganta. Diarreia, náusea ou vômito se manifestaram em algumas delas, e um caso apresentou conjuntivite (Tabela 1).

Algumas pessoas foram tratadas empiricamente com drogas antibacterianas ou antivirais, e todos receberam tratamento sintomático com analgésicos, antiinflamatórios ou corticoesteroides. Os que entraram em óbito receberam cuidados intensivos de suporte, visto que evoluíram com falência cardiorrespiratória refratária.

Os exames laboratoriais dos falecidos mostraram padrão leucocitário compatível com supressão medular comumente verificável em fases hiperagudas de infecções virais, ou estresse sistêmico orgânico agudo, perda de função renal e acidose metabólica com resposta ventilatória de compensação. Esse quadro foi observado na presença de elevado gradiente alvéolo-arterial de oxigênio, tendência à hipocalemia, e $\mathrm{PaO}_{2} / \mathrm{FiO}_{2}$ e ânion-gap normais, apontando para substrato fisiopatogênico sustentado primariamente em falência circulatória, a qual pode ter levado a prejuízos na hematose por disfunção perfusional sem outro comprometimento pulmonar, e acidose tubular renal secundária ao distúrbio hemodinâmico.

A interpretação, até aquele momento, foi de que o evento se tratava de uma síndrome febril aguda de transmissão interpessoal por via oronasofaringeana, cujos sintomas surgiam dentro de uma semana após o contágio. Podia haver complicação circulatória imuno mediada por uma resposta indutora de disfunção endotelial que se manifestou na segunda semana de início dos sintomas, levando, secundariamente, à falência aguda das trocas gasosas e da função renal, provavelmente cursando com baixo consumo periférico de

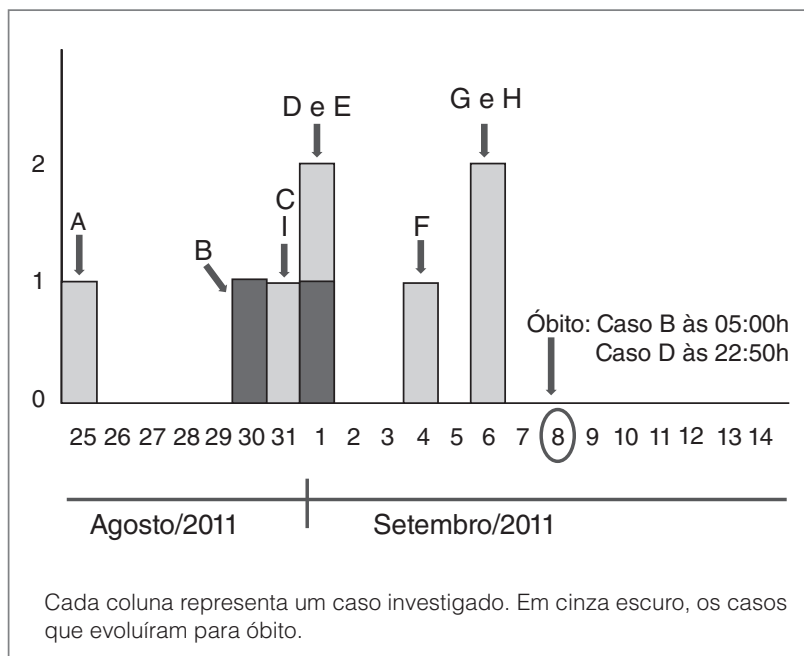

Figura 1: Data de início dos sintomas dos primeiros casos da Síndrome Febril Aguda ocorrida em São Carlos (SP) no segundo semestre de 2011, com destaque para os dois casos que evoluíram para óbito e a data em que faleceram

Tabela 1: Distribuição proporcional das manifestações clínicas presentes nos primeiros sete casos sintomáticos da Síndrome Febril Aguda (São Carlos, 25 de agosto a 6 de setembro de 2011)

\begin{tabular}{|l|c|c|c|}
\hline $\begin{array}{l}\text { Manifestação } \\
\text { clínica }\end{array}$ & $\begin{array}{c}\text { Ocorrência } \\
\text { (\%) }\end{array}$ & $\begin{array}{c}\text { Manifestação } \\
\text { clínica }\end{array}$ & $\begin{array}{c}\text { Ocorrência } \\
\text { (\%) }\end{array}$ \\
\hline $\begin{array}{l}\text { Dor/irritação de } \\
\text { garganta }\end{array}$ & 100 & Exantema & 62 \\
\hline Febre & 75 & Náusea & 50 \\
\hline Tosse & 75 & Petéquias & 50 \\
\hline Mialgia & 75 & Artralgia & 37 \\
\hline Inapetência & 75 & Vômitos & 37 \\
\hline Cefaleia & 62 & Dispneia & 37 \\
\hline Coriza & 62 & Diarreia & 25 \\
\hline Mal estar & 62 & $\begin{array}{c}\text { Insuficiência } \\
\text { respiratória }\end{array}$ & 25 \\
\hline Astenia & 62 & $\begin{array}{c}\text { Outras } \\
\text { manifestações }\end{array}$ & 25 \\
\hline
\end{tabular}

*Dor retroorbital, diminuição de peso, cianose de extremidades e edema periférico 
oxigênio. Não tinham sido, ainda, identificados os fatores que favoreceram o desenvolvimento de complicações, mas os casos investigados sugeriam, clínico-epidemiologicamente, que o principal fator poderia estar relacionado ao padrão da resposta imunológica individual à invasão pelo agente etiológico. Entre os indicadores laboratoriais de complicação foram encontrados leucopenia, com aumento proporcional de neutrófilos, e linfopenia relativa; gasometria arterial com aumento do gradiente alvéolo-arterial de oxigênio, excesso de bases anormalmente negativo, com resposta compensatória pulmonar ou hipoxemia com $\mathrm{PaCO}_{2}$ no limite inferior, além de elevação da ureia e da creatinina sérica.

Assim, em algumas horas a partir da notificação, já havia sido alcançado o primeiro objetivo da investigação epidemiológica, relacionado ao conhecimento da forma da transmissibilidade do agravo destinado à adoção de medidas preventivas e ações de bloqueio, e parte do segundo objetivo de esclarecimento da sua fisiopatogenia, com finalidade de redução das complicações clínicas e adoção de medidas adequadas de assistência. Imediatamente foram divulgadas orientações preventivas à comunidade, emitiram-se orientações aos serviços e profissionais de saúde para a vigilância epidemiológica e o atendimento de pessoas com manifestações clínicas suspeitas do agravo, e traçou-se um conjunto de ações de monitoramento e sequência do processo de vigilância e investigação.

Entre as ações, definiu-se como caso, para fins de notificação e investigação, "pessoa com febre de início recente acompanhada de tosse, dor de garganta ou exantema, e história de contato ou comunicação com caso semelhante".

A partir deste momento, a investigação epidemiológica qualificou e ampliou o questionário aplicado na fase preliminar do inquérito para o levantamento das informações sobre as pessoas notificadas segundo o novo critério de definição de caso e assumiram-se como objetivos não só as ações de vigilância em saúde como também as relacionadas à busca pelo diagnóstico clínico e etiológico do problema. A esse respeito, focalizaram-se como possibilidades as doenças respiratórias agudas, as exantemáticas e as zoonóticas potencialmente relacionáveis às manifestações clínicas dos casos.

Laboratorialmente foram investigados Dengue (NS1, IgM e IgG, RT-PCR no soro); Influenza (RT-PCR nas secreções das vias respiratórias); Hantavírus (IgM no soro e Imunohistoquímica); Leptospirose (IgM e PCR no soro); Febre amarela (RT-PCR e Mac-ELISA no soro); RT-PCR para Streptococcus pyogenes; RTPCR para gripe A (H1N1 e H3N2); PCR no soro para Meningites bacterianas e Enterovírus; Febre maculosa (IgM e IgG no soro); e PCR no soro para Riquétsias.

O laudo da necropsia de um dos falecidos, emitido no terceiro dia de início da investigação, referiu "pulmão de choque" sem eventos hemorrágicos. Sete dias depois, o laboratório designado pela Secretaria da Saúde do Estado de São Paulo informou o achado de Streptococcus pyogenes em todos os espécimes viscerais do corpo necropsiado, inclusive nos naturalmente estéreis, preenchendo os critérios do Working Group on Severe Streptococcal Infections do CDC para Síndrome do Choque Tóxico Estreptocócico ${ }^{7}$.
A partir daí, algumas questões foram levantadas: o risco de uma epidemia letal provavelmente era inexistente ${ }^{3,4,8,9}$; ainda que o surto fosse concentrado, deveria ser contido; tornou-se necessário alertar os profissionais da assistência para o diagnóstico correto e o tratamento adequado de agravos de transmissão respiratória, especialmente as estreptococcias.

Quanto ao tratamento, destaque especial foi dado à prescrição de antiinflamatórios não esteroides a pessoas com doenças infecciosas em vias respiratórias altas devido à sua prática frequente no cotidiano. A preocupação surgiu no sentido da relação risco-benefício dessa prática, uma vez que esses medicamentos não favorecem o curso da doença e ainda carreiam o potencial de complicá-lo, seja por seus efeitos colaterais, efeitos tóxicos ou pela possibilidade de influenciarem desfavoravelmente as respostas imunológicas $^{11}$, podendo, neste caso, tanto dificultar as defesas do organismo quanto facilitar a desregulação da resposta em detrimento da homeostasia orgânica.

Assim, foram tomadas as seguintes medidas: manutenção da vigilância epidemiológica; recomendação da administração de uma dose terapêutica de penicilina benzatina em todas as pessoas notificadas no momento do primeiro atendimento médico; orientada a não administração de antiinflamatórios; sugerido tratamento sintomático, em casos selecionados, apenas com dipirona ou paracetamol; recomendado o acompanhamento da evolução clínica da pessoa até o seu desfecho final; e indicado tratamento de suporte e antibioticoterapia específica antiestreptoccócia intravenosa a todos os casos graves em tratamento hospitalar.

Até 29 de setembro de 2011 foram investigadas 368 pessoas com manifestações definidoras da Síndrome Febril Aguda, segundo o critério estabelecido pelo serviço local de vigilância epidemiológica. Todos tiveram evolução benigna mediante tratamento ambulatorial. Nenhum indivíduo evoluiu com complicação, e apenas dez precisaram de cuidados hospitalares; ainda assim, não demandaram tratamento intensivo. Não houve mais nenhum óbito por SCT estreptocócico.

Retrospectivamente, foi encontrado, por busca ativa, o caso de uma criança de cinco anos que foi a óbito por falência cardiocirculatória de evolução rápida após um evento agudo de faringoamigdalide dois meses antes do caso-índice desta investigação. Não achamos, nos arquivos médicos dessa criança, informações que confirmassem o diagnóstico etiológico, nem dado sobre realização de necropsia. Tampouco a ocorrência era de conhecimento do Serviço de Vigilância em Saúde até o momento dessa busca ativa.

A vigilância foi mantida até novembro do mesmo ano, quando encerraram os trabalhos de investigação do evento.

\section{DISCUSSÃo}

A evolução da humanidade se caracterizou por um modo de produção econômica e social significativamente influenciado pela evolução tecnológica e mercadológica ${ }^{12}$. Especialmente nos últimos 100 anos, isso vem proporcionando um movimento 
ecossistêmico global de intensidade e celeridade suficiente para possibilitar, entre outras coisas, o surgimento de novos agravos à saúde, acompanhados por novos modos de abordagem do fenômeno saúde-adoecimento, tanto no plano individual quanto no coletivo. Nesse contexto, apresentam-se as doenças emergentes e reemergentes a violarem a transição epidemiológica que se delineava até meados do século $\mathrm{XX}^{13-15}$.

Impõe-se, pois, a necessidade de adequada qualificação dos sistemas e serviços de saúde para a vigilância e o controle de agravos inusitados. Não obstante, a epidemiologia descritiva continua sendo uma ferramenta estratégica para controle de surtos, mesmo antes da identificação da doença em curso e de seu agente etiológico ${ }^{11,13}$.

Nesse caso, ao permitir identificar as fontes de contaminação ou infecção e os meios de transmissão de um determinado agravo, independente de sua identificação prévia, a epidemiologia descritiva assegura possibilidades para o seu controle, com consequente redução dos danos por ele causados ${ }^{11,13}$.

A experiência relatada neste artigo foi uma aplicação prática dos princípios da epidemiologia descritiva, destinados à abordagem de um agravo inusitado. Ao buscar um conjunto hierarquizado de respostas por meio de um algoritmo formatado com enfoque na agilidade das ações (Figura 2), seus objetivos foram alcançados na medida esperada.

A investigação epidemiológica executada possibilitou a adoção de medidas de controle já nas primeiras oito horas após a notificação do primeiro caso, as quais se confirmaram procedentes a partir da identificação do agravo em curso e seu agente etiológico, ocorrida no décimo dia após o início dos trabalhos.

Surtos concentrados de SCT estreptocócico, semelhante ao relatado, vêm sendo descritos desde 1980 e são considerados uma condição reemergente, cuja letalidade pode alcançar $70 \% \%^{1,3,4,8,9,15}$.

É mais comum que ele se desenvolva a partir de infecções estreptocócicas graves, ainda que possa ocorrer a partir de quadros com baixa gravidade inicial. No evento em São Carlos, à semelhança de outros surtos já relatados na literatura, a SCT estreptocócico se desenvolveu a partir da infecção e colonização das vias aéreas superiores de pessoas jovens previamente sadias ${ }^{3,4,8,9}$.

Tal síndrome se instala abruptamente, costuma ser refratária às medidas de suporte e pode levar a óbito no prazo de algumas horas por falência cardiocirculatória e renal agudas, conforme ocorreu com os casos apresentados. Geralmente, é precedido por uma infecção localizada em partes moles ou vias respiratórias, e é comum afetar pessoas previamente sadias, a exemplo do que foi exposto $^{1-5,8,9}$. O tratamento específico é feito com penicilina ou clindamicina, e imunoglobulina intravenosa nos casos que evoluem com $\mathrm{SCT}^{2,4}$.

O modelo globalizado vigente de vida em sociedade tem possibilitado a ruptura da transição epidemiológica que se verificava até meados do século XX ao dar margem à emergência de novos e à reemergência de velhos agravos infectocontagiosos.

Esse fenômeno exige que os serviços de vigilância em saúde sejam mantidos em estado permanente de alerta em relação a novos

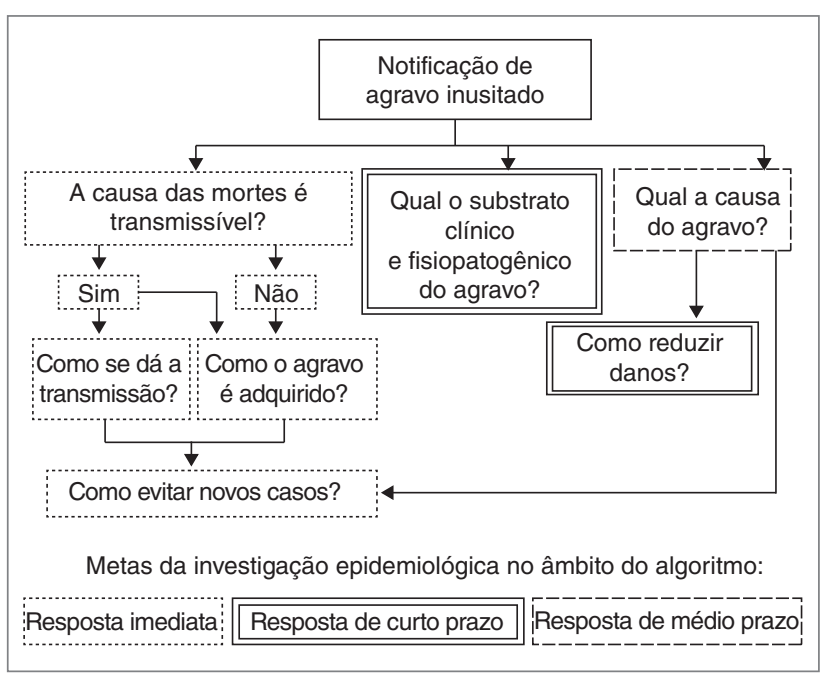

Figura 2: Objetivos de um inquérito epidemiológico destinado ao esclarecimento e controle de um agravo inusitado

problemas que podem surgir de modo abrupto e evoluir de forma imprevisível, bem como desenvolvam agilidade suficiente para uma resposta rápida de controle epidemiológico.

No que diz respeito à SCT Estreptocócico, ainda que não tenham ocorrido situações epidemiológicas de maior intensidade ou repercussão, a ocorrência frequente de pequenos surtos, as mudanças ecossistêmicas no planeta e a própria evolução biológica dos seres vivos subtraem garantia de que não corremos o risco desse agravo acontecer em proporções preocupantes.

O desenvolvimento tecnológico voltado a diagnósticos é muito importante e tem contribuído substancialmente para a identificação e o controle de inúmeros agravos na população. Entretanto, a epidemiologia descritiva continua sendo ferramenta estratégica, indispensável, eficiente e eficaz para os objetivos da vigilância em saúde, apropriável até mesmo por serviços pouco aparelhados por tecnologias duras.

No que diz respeito ao cuidado individual, é importante que os profissionais da assistência também fiquem alertas à identificação, ao diagnóstico, monitoramento e abordagem terapêutica adequados das doenças estreptocócicas, fundamentados na evidência científica, no princípio ético da não maleficência e na racionalidade terapêutica.

\section{AGRADECIMENTOS}

As pessoas e instituições a seguir apoiaram significativamente a investigação relatada neste artigo: Arthur Goderico Fonghieri Pereira, Ana Lúcia Bernardo Soares e Edeltraut Nothling Zóia, da Secretaria Municipal de Saúde de São Carlos (SP); Maria Tereza Claro, do Grupo de Vigilância Epidemiológica XII de Araraquara (SP); Carolina Bonelli Spadacini e Priscila Fernanda Marretti, do Núcleo Hospitalar de Epidemiologia da Irmandade Santa Casa de Misericórdia de São Carlos; e ao Laboratório de Saúde Pública de São Paulo - Instituto Adolfo Lutz. 


\section{REFERÊNCIAS}

1. Ato $M$, Ikebe $T$, Kawabata $H$, Takemori $T$, Watanabe $H$. Incompetence of neutrophils to invasive group A streptococcus is attributed to induction of plural virulence factors by dysfunction of a regulator. PLoS ONE. 2008;3(10):e3455.

2. Johansson L, Thulin P, Low DE, Norrby-Teglund A. Getting under the skin: the immunopathogenesis of Streptococcus pyogenes deep tissue infections. Clin Infect Dis. 2010;51(1):58-65.

3. Ayala-Guaytán JJ, Gujardo-Lara CE, Valdovino-Chávez SB. Fascitis necrotizante y choque tóxico en infección por estreptococo grupo A. Rev Med Inst Mex Seguro Soc. 2011;49(4):425-32.

4. Wessels MR. Infecções estreptocócicas e enterocócicas. In: Braunwald E, Fauci AS, Kasper DL, Hauser SL, Longo DL, Jameson JL. Harrison: medicina interna. $15^{\text {th }}$ ed. Rio de Janeiro: McGraw-Hill; 2008.

5. Kahn F, Mörgelin M, Shannon O, Norrby-Teglund A, Herwald H, Olin $\mathrm{Al}$, et. al. Antibodies against a surface protein of Streptococcus pyogenes promote a pathological inflammatory response. PLoS Pathog. 2008;4(9):e1000149.

6. Darenberg J, Luca-Harari B, Jasir A, Sandgren A, Pettersson H, Schalén C, et. al. Molecular and clinical characteristics of invasive group A streptococcal infection in Sweden. Clin Infect Dis. 2007;45(4):450-8.

7. Centers for Disease Control and Prevention [Internet]. Streptococcal Toxic-shock syndrome (STSS) (Streptococcus pyogenes): 2010 case definition. Disponivel em: http://wwwn. cdc.gov/NNDSS/script/casedef.aspx?CondYrID=858\&DateP $u b=1 / 1 / 2010 \% 2012: 00: 00 \% 20$ AM Acesso em: 10 mai. 2013.
8. Lamagni TL, Darenberg J, Luca-Harari B, Siljander T, Efstratiou A, Henriques-Normark B, et al. Epidemiology of severe Streptococcus pyogenes disease in Europe. J Clin Microbiol. 2008;46(7):2359-67.

9. Ortega-Mendi M, Martínez-Martínez L, Aledo-Linos AG, AgüeroBalbín J, Viloria-Raymundo L, Cano-García ME, et al. Brote de síndrome de shock tóxico esptreptocócico en una guardería de Cantabria en 2006. Rev Esp Salud Publica. 2008;82(1):81-9.

10. Albuquerque EM. Avaliação da técnica de amostragem "RespondentDriven Sampling" na estimação de prevalências de doenças transmissíveis em populações organizadas em redes complexas. Dissertação (Mestrado) - Escola Nacional de Saúde Pública (ENSP) da Fundação Oswaldo Cruz (FIOCRUZ), Rio de Janeiro, 2009.

11. Bricks LF. Uso de antiinflamatórios não-hormonais em crianças com doenças virais vs risco potencial para síndrome de Reye e doenças invasivas graves por estreptococos do grupo A. Pediatr. 2000;22(1):35-43.

12. Silva LJ. Doenças emergentes e desafios à saúde pública. O case de São Paulo. Cad Saúde Pública. 2011;17(Suppl.):141-6.

13. Barata RCB. O desafio das doenças emergentes e a revalorização da epidemiologia descritiva. Rev Saúde Pública. 1997;31(5):531-7.

14. Gallardo SD, Garcia IJ, Arizcuren EM, Nuñez AR. Síndrome de shock tóxico estreptocócico: ¿una enfermedad emergente? An Pediatr. 2009;70(3):310-1.

15. Souto BGA. Fundamentos epidemiológicos para a abordagem das doenças infecciosas. Rev Méd Minas Gerais. 2009;19(4):364-71. 